\title{
Overview on: Herbs Use in Treatment of Primary Dysmenorrhea (Menstrual Cramps)
}

\author{
Bharti Goel $^{1}$, Neelesh Kumar Maurya ${ }^{2, *}$ \\ ${ }^{1}$ Department of Foods and Nutrition, Government Home Science College, Panjab University, India \\ ${ }^{2}$ Department of Foods and Nutrition, Institute of Home Science, Bundelkhand University, India
}

Received September 24, 2019; Revised November 21, 2019; Accepted November 26, 2019

Copyright $\odot 2019$ by authors, all rights reserved. Authors agree that this article remains permanently open access under the terms of the Creative Commons Attribution License 4.0 International License

\begin{abstract}
Sexual Maturation and pubertal development is the period of adolescence from childhood to adult life. Adolescence is a transition from girl to motherhood that is accompanied by various changes in Cognition, Pubertal development, changes in Hormones, Physical development, Psychological and physiological changes occur simultaneously. Hence, "menarche is the onset of puberty in adolescent girl characterized by excessive bleeding, irregular menstruation, face problems such as acne and dysmenorrhoea". So, to identify Relevant Randomized Controlled Trials (RCTs), Cochrane Menstrual Disorders, Scopus, Dysmenorrhoea Group Register of controlled trials, PubMed, Google Scholar and Medline were some of the electronic searches. Therefore, to treat primary dysmenorrhoea or to prevent herbal medicine can be used alone or with other therapies (pharmaceutical, nutritional, and hydrotherapy).
\end{abstract}

Keywords Herb, Dysmenorrhoea, Menstrual Cramps, Black Cohosh, St. John's Wort, Ananas Comosus

\section{Introduction}

Dysmenorrhoea is also known as menstrual cramps [1]. it is derived from the Greek words dys, meaning difficult/painful/ abnormal; meno, month; and rrhea, to flow. In women's reproductive years, dysmenorrhoea is one of the most common gynaecological conditions that affect the quality of life. In India, $40.7 \%$, United States of America $85 \%$ and Italy $84.1 \%$ were estimated prevalence rates [2]. During menstruation and few days before menstruation as well as normally subsides as menstruation finishes occurring dysmenorrhoea. Primary dysmenorrhoea is occurring in the absence of uterine condition while secondary is due to pathology condition of pelvic. Symptoms caused by dysmenorrhoea caused by high levels of prostaglandins (pain and inflammation hormone), nausea or dizziness, loose stools (diarrhoea), irritability, headaches and Menstrual cramps without an endometriosis, uterine fibroids, pelvic inflammatory disease (underlying health condition) that mainly occurs during the first few days and just before a woman's menstrual period. But if persist for severe cramping, one must consult to doctor $[1,3,4]$. There are various risk factors which are associated with the period of primary dysmenorrhoea are poor sleep, hygiene, alcohol, cigarette smoking, caffeine consumption, a family history of dysmenorrhoea, lack of exercise, obesity, stressful lifestyle, dietary habits, and long menstrual cycles [5]. In the adolescent populations, spasmodic rates of dysmenorrhoea ranging from $16 \%$ to $91 \%$ were revealed from the published studies [6]. This review emphasis on dysmenorrhoea management by the therapeutics use of herbs.

\section{Searching Methods}

The reference lists of included trials, AMI, AMED, Health Source Nursing/Academic Edition, BioMed Central gateway, AARP Angeline, MEDLINE, International Pharmaceutical Abstracts, PsycINFO, CINAHL, Natural medicines comprehensive database, EMBASE, TRIP database, CAM on PubMed, CENTRAL, and clinical trial registers Herbs in the Treatment of dysmenorrhoea are as follows:

\section{- Zingiber Officinale}

Ginger herb helps to soothe troubles in menstrual and ease cramps by decrease the levels of pain-causing prostaglandins (premenstrual syndrome). Ginger capsule 250mg taken four times a day for three days were got relief in menstrual cramps with ibuprofen [7]. Another study in 2012 published in BMC Complementary and Alternative 
Medicine examined that moderate or severe primary dysmenorrhoea with the use of ginger root powder or a placebo in 120 women were seen significant differences in the severity of pain between both the groups [8]. Thus, it can be an inference that uses of ginger root powder in the form of tea before onset and first three days of menstrual periods provides a soothing effect and can short the duration of periods of menstrual pain and to relieve cramps [9].

\section{- Fennel (Foeniculum vulgare)}

Fennel contains anethole (a compound with anti-spasm effects) with a crunchy texture like celery and taste like liquorice that helps to ease menstrual cramps [10]. In 2015, one study revealed that both fennel and vitagnus had a greater effect as compared with the mefenamic acid after the two days of intervention on 105 women suffering from primary dysmenorrhoea in the Iranian Journal of Nursing and Midwifery Research.[11]

\section{- $\quad$ Pycnogenol (Extract French Maritime Pine Bark)}

This supplement Pycnogenol is Extracted from the pine trees bark (Pinus maritima) that helps to reduce pain [12]. In 2014 a small study conducted with pycnogenol revealed also same to reduce pain with an intake of oral contraceptive for three months and no significant evidence was found by the herb Cochrane supplement on other chronic conditions [13, 14].

\section{- $\quad$ Black Cohosh (Actaea racemose)}

Black cohosh is a plant named from its black roots grows in Canada and the United States from June to September which is used in various medical conditions. It has various healing properties like rheumatoid arthritis, kidney, sore throat, joint inflammation, malaria, menstrual cramps, labour pain that can be taken in form of tea, capsule (Remifemin $20 \mathrm{mg}$ of black cohosh extract) and the herbal mixture is also recommended as 20 to $40 \mathrm{mg}$ in menopause [15]. Black cohosh can be used as herbs as treatment for six months or less in menopause by the American College of Obstetrics and Gynaecology guidelines [16]. Agrimony (Agrimonia pilosula) and shepherd's purse (Capsella bursa-pastoris) are best-known herbs in China, Europe and Germany to reduce bleeding and to treat profuse menstruation by coagulating blood up to 50\% [17]. Whereas Shepherd's purse act as urinary antiseptic and anti-haemorrhagic that contains vitamin C, potassium salts, flavonoids, and rutin in mild menorrhagia and metrorrhagia [18].

\section{- Buckwheat (Fagopyryum esculentum)}

Herb like buckwheat (Fagopyryum esculentum), rutin is isolated flavonoid that helps to control bleeding and to reduce capillary fragility [19].

\section{- $\quad$ Cramp Bark (Viburnum opulus)}

In anovulatory disorders, dong quai root (Angelica sinensis), black cohosh root (Cimicifuga racemosa), and anise seed (Pimpinella anisum) are very useful. cramp bark (Viburnum opulus) acts as a uterine sedative for relieving uterine and abdominal cramps [20,21].

\section{- $\quad$ Puff Ball (Bovista)}

Bovista helps to cure menstrual irregularity, restrict blood circulation, and trauma. It is also used with charcoal fumes inhalation in remedies of asphyxiation mentioned by E. A. Farrington in Lectures on Clinical Materia Medica (1889). Bovista also assists in ovarian cysts, diabetes mellitus, stuttering or stammering children, palpitation after a meal, awkwardness in speech and action [22].

The calendula oil obtained marigold flowers. It shortens axons of nerve cells that prevent messages transmission from nerve cells of uterus to the brain which leads to late transfer of pain messages from the brain to the uterus. In one of a clinical trial, Menastil lotions help in reducing the severity of dysmenorrhoea and its symptoms than placebo. Furthermore, the use of sedative consumption of calendula oil helps to decrease menstrual bleeding [23,24].

\section{- $\quad$ Cuminum Cyminum}

C. cyminum is very helpful for the treatment of menstrual cramps, gastrointestinal diseases and delayed menstruation [26]. In one of randomized clinical trial, subject was divided into 5 groups, among them, three groups were consumed C. cyminum capsules (65 mg) (1 capsule/TID, 2 capsules/TID and, the 3rd group, 1 capsule/BID), one group was on mefenamic acid and the last group consumed a placebo capsule that showed significant difference in decreasing pain intensity in the first and second periods among consumers of $C$. Cyminum who had 2 capsules/ TID equals to mefenamic capsule per $8 \mathrm{~h}$ [25].

\section{- Matricaria Chamomilla}

M. chamomilla is a herbal drug that acts as antispasmodic, anti-anxiety, sedative and anti-inflammatory effects [26]. In three studies $M$. Chamomoilla showed improvement rate in dysmenorrhea than placebo $[27,28]$. In the first study after one month, $M$. Chamomoilla tea was significantly different in the intervention group and control group [23, 29]. In the second study, M. Chamomoilla helps in reducing pain than mefenamic acid. In the third study effects of $M$. chamomilla with $F$. Vulgar had a significant effect on dysmenorrhea and premenstrual syndrome, abdominal pain, pelvic, and anger. Whereas for reducing fatigue and lethargy, $F$. Vulgare had shown the more effective result [30].

\section{- Valeriana Officinalis}

Since 11 century, $V$. Officinalis is traditional medicine that acts as menstruating herb and sedative drug but in a clinical trial had no effect on duration and severity of 
bleeding. V. Officinalis roots have valerian essential oil which contains valepotriates that used as a sedative, diuretic, muscular antispasmodic and antispasmodic properties in valerenic acid roots [29]. It also inhibits cell depolarization with contraction and blocks channels of calcium [30]. In various studies conducted on the effect of roots of $V$. Officinalis with placebo and also with mefenamic acid. Result of above studies reviewed that pain reduction in $V$. officinalis was effective compared to placebo and the same effect was seen with mefenamic acid. In another research with $V$. Officinalis capsules showed that symptoms of dysmenorrhea were reduced compared to pre-intervention [31,32].

\section{- Cinnamomum Zeylanicum}

C. zeylanicum consists of sugar, essential oil, tannin, mucilage, resin, calcium oxalate, and pigment in the Lauraceae family that has an antispasmodic effect attributed to essential oil and tannin [33]. Cinnamaldehyde and eugenol is the main component of cinnamon essential oil. C. zeylanicum capsule was compared in a triple-blind study that showed a statistically significant difference in dysmenorrhea severity than placebo $(34,35)$.

- Stachys lavandulifolia

S. lavandulifolia was excessively found in Iran and Alvand Mountain that is mainly famous for spasm treatment (menstruating agent in women), increases sexuality, abortion and pain killer (23). In various studies, $S$. Lavandulifolia inhibits prostaglandins production, stomach pain and painful menstruation [36]. In one study, infused plant powder with S. Lavandulifolia prescribed for three times that showed no significant difference in pain duration and severity before and after using S. lavandulifolia [23, 37,38].

\section{- Zataria Multiflora}

In the family of mint, Z. Multiflora has been found whose essential oil is carvacrol and thymol. Z. Multiflora has various effects to rectify bloating, respiratory diseases, seizures, smooth muscle spasm and effect on antimicrobial and antispasmodic effect in the study of ancient physicians $[39,40]$ by depolarization of cell and blockage of calcium channel, Z. multiflora can inhibit contractions stated by Van den Broken in a study of randomly divided participants in three groups that first on placebo, second, and third on (1\%) and (2\%) of Z. multiflora essential oil. Z. multiflora leaves had a similar effect to that of mefenamic acid on pain reduction [25].

\section{- Mentha Piperita}

In traditional medicine M. Piperita has antispasmodic properties for smooth muscles inhibits induced contractions by cell depolarization and blocks calcium channels (40). M. Piperitaherb has a pungent taste with a greenish-yellow, pale yellow or colourless obtained from fresh twigs and flowers distillation. With ibuprofen, the effect of M. Piperita extract was compared in one study that resulted in reducing pain [41].

\section{- Vitex Agnus-Castus}

Vitex agnuscastusis used as herbal medicine in menstrual disorders [42]. Vitagnous ${ }^{\circledR}$ is a herbal drop derived from $V$. agnuscactus plants that have a dopaminergic effect. V. agnus-castus combination helps to reduce FSH and LH secretion, increase progesterone, affect hypothalamus-pituitary axis, and thus increase or decrease hormonal balance naturally. In a study reported that Vitagnous ${ }^{\circledR}$ was more effective in pain reduction intensity than placebo [23].

\section{- Echinophora Platyloba}

In Apiaceae family, E. Platyloba is endemic plants in Iran that is mostly distributed in Mediterranean region as $E$. Platyloba extract have various effect in reducing muscle contraction and antispasmodic effects can inhibit intestinal irritability completely [42]. In this field two studies were reviewed are as follows: E. platyloba extract compared with placebo that showed significant difference with placebo in terms of reducing pain intensity and another study with the effect of fennel and E. platyloba extract on reducing dysmenorrhoeal severity. Further, E. platylobaand $F$. Vulgare effect also helpful in decreasing the severity of dysmenorrhea [43].

\section{- $\quad$ Achillea Willhemsii}

In the Asteraceae (Compositae) family, A. willhemsii has anti-prostaglandin, the anti-inflammatory effect due to inhibition of arachidonic acid metabolism [44]. In a reviewed study with $A$. willhemsii extracted capsule was prescribed to 70 dysmenorrhoeal college students at every $6 \mathrm{hr}$ in which they can reduce the consumption by half but cannot exceed consumption by 4 capsules. Result of study showed that in the first three days pain reduction was significant with treatment and compared with the cycles without treatment [23].

\section{- St. John's Wort (Hypericum Perforatum)}

St. John's wort is also called as Hypericum perforatum. it was very useful in various disease such as nerve pain (neuralgia), insomnia, swelling, confusion, crying, headaches, tension, anxiety, depression (NCCAM 2014), poor coordination, food cravings and improve pain and mood symptoms (Canning 2010) .St. John's wort extract is also aid in irritability, insomnia, sciatica, irregular menstruation, rheumatoid arthritis, and also influence the serotonergic system (Ghazanfarpour 2011) [45]. In an open-label trial, 19 PMS women were administered with St. John's wort extract for 2 cycles of menstruation that showed an average decrease in 51\% symptom scores by the trial end and 50\% in severity symptom reduction in two-third participants (Stevinson 2000) [46]. 


\section{- $\quad$ Ananas Comosus (Pineapple)}

Pineapple fruit (Ananas comosus (L.) is also used as a meat tenderizer and remedy for inflammatory reactions pineapple consists a mixture of compound ingredients bromelain that acts as a protease inhibitor and helps in reducing irritation, cramps, bloating in menstruation, increase post-traumatic wound healing, immune modulator with anti-tumour and anti-cancer activity. Hence, bromelain in pineapple considered as potential phytomedicine and also relieves primary dysmenorrhea pain by acting as herbal remedies $[47,48]$.

\section{Conclusions}

Dysmenorrhoea is a medical condition that affects mainly young women. It can be multifactorial, inflammatory mediators, pain pathways and a centralised response. With an individualised to combine approach, women can get relief from pain by rejecting the multiple underlying mechanisms. Based on a high degree of safety/ efficacy, long historical uses, numerous herbs can be recommended for primary dysmenorrhoea. Patients who have not tolerated NSAIDs or wish to avoid them can certainly attempt to substitute a herbal spasmolytic and inflammation modulator. Uterine astringents can be given in case of menorrhagia history or chronic problems and many herbs or herbal medicine can be recommended in hormone-modulating herbs. many Vitexagnus-castus (chaste tree) or Cimicifuga racemosa (black cohosh) root and pelvic lymphagogues, such as Fouquieria splendens (ocotillo) bark should be treated completely not just symptoms in primary dysmenorrhea. Many herbs can be combined with conventional and nutritional/ supplemental approaches in this review paper to rectify primary dysmenorrhea. These herbs should be viewed as useful multifaceted tools with real potential to help patients as their long historical uses may not be as well-documented but are still important for directing clinical practice.

\section{REFERENCES}

[1] Zhang X, Zhang R, Chen D, Huang R, Tian Y, Zhang P, et al. Association of tea drinking and dysmenorrhoea among reproductive-age women in Shanghai, China (2013-2015): a cross-sectional study. BMJ; 2019 Apr; 9(4): e026643

[2] Ou M-C, Hsu T-F, Lai AC, Lin Y-T, Lin C-C. Pain relief assessment by aromatic essential oil massage on outpatients with primary dysmenorrhea: A randomized, double-blind clinical trial. Journal of Obstetrics and Gynaecology Research [Internet]. Wiley. 2012; 38(5): 817-22p.

[3] Acheampong K, Baffour-Awuah D, Ganu D, Appiah S, Pan $\mathrm{X}$, Kaminga A, et al. Prevalence and Predictors of Dysmenorrhea, Its Effect, and Coping Mechanisms among
Adolescents in Shai Osudoku District, Ghana. Obstetrics and Gynecology International [Internet]. Hindawi Limited. 2019; 20: 1-7p.

[4] Proctor M, Farquhar C. Diagnosis and management of dysmenorrhoea. BMJ; 2006; 332(7550): 1134-8p.

[5] ernández-Martínez E, Onieva-Zafra MD, Parra-Fernández ML. Lifestyle and prevalence of dysmenorrhea among Spanish female university students. Palazón-Bru A, editor. Public Library of Science (PLoS). 2018; 13(8): e0201894p.

[6] Pellow J, Nienhuis C. Medicinal plants for primary dysmenorrhoea: A systematic review. Complementary Therapies in Medicine Elsevier BV. 2018; 37: 13-26p.

[7] Nieman DC, Shanely RA, Luo B, Dew D, Meaney MP, Sha W. A commercialized dietary supplement alleviates joint pain in community adults: a double-blind, placebo-controlled community trial. Nutrition journal. 2013; 12(1): 154p.

[8] Ou MC, Hsu TF, Lai AC, Lin YT, Lin CC. Pain relief assessment by aromatic essential oil massage on outpatients with primary dysmenorrhea: A randomized, double-blind clinical trial. Journal of Obstetrics and Gynaecology Research. 2012; 38(5): 817-22p.

[9] Kafash-Farkhad N, Asadi-Samani M, Rafieian-Kopaei M. A review on phytochemistry and pharmacological effects of Prangosferulacea (L.) Lindl. Life Science Journal. 2013; 10(SUPPL): 360-7p.

[10] Zeraati F, Shobeiri F, Nazari M, Araghchian M, Bekhradi R. Comparative evaluation of the efficacy of herbal drugs (fennelin and vitagnus) and mefenamic acid in the treatment of primary dysmenorrhea. Iranian journal of nursing and midwifery research. 2014; 19(6): 581p.

[11] Suzuki N, Uebaba K, Kohama T, Moniwa N, Kanayama N, Koike K. French maritime pine bark extract significantly lowers the requirement for analgesic medication in dysmenorrhea: a multicenter, randomized, double-blind, placebo-controlled study. The Journal of reproductive medicine. 2008; 53(5): 338-46 p.

[12] Dugall M, Luzzi R, Hosoi M, Corsi M, Belcaro G. Improvements of Venous Tone with Pycnogenol in Chronic Venous Insufficiency: An Ex Vivo Study on Venous Segments. International Journal of Angiology. 2014; 23(01): 047-52p.

[13] Stojanovska L, Kitanovaska V. The effect of complementary and alternative therapy at menopause: trick or treat. Current Topics in Menopause. 2013; 22: 1(413): 385p.

[14] Quaas AM, Weedin EA, Hansen KR. On-label and off-label drug use in the treatment of endometriosis. Fertility and sterility. 2015; 103(3): 612-25p.

[15] Teacake R, Bahre R, Genthner A, Fuchs J, Schmidt-Taenzer W, Wolff A. Suspected black cohosh hepatotoxicity-challenges and pitfalls of causality assessment. Maturitas. 2009; 63(4): 302-14p.

[16] Baker E, Saha S. Forest farming in Georgia, United States: Three potential crops. Annals of Agrarian Science. 2018; 16(3): 304-8p.

[17] Ody P. The complete medicinal herbal: a practical guide to the healing properties of herbs. Simon and Schuster; sky 
horse publishing, New York, U.S.A. 2017;1-28

[18] Al-Snafi AE. The chemical constituents and pharmacological effects of Capsella bursa-pastoris-A review. International Journal of Pharmacology and toxicology. 2015; 5(2):76-81p.

[19] Dietrych-Szostak D, Oleszek W. Effect of Processing on the Flavonoid Content in Buckwheat (Fagopyrum esculentum Möench) Grain. Journal of Agricultural and Food Chemistry [Internet]. American Chemical Society (ACS); 1999 Oct; 47(10): 4384-7 p.

[20] Mayo JL. A healthy menstrual cycle. ClinNutr Insights. 1997; 5(9):1-8 p.

[21] Nahid K, Fariborz M, Ataolah G, Solokian S. The effect of an Iranian herbal drug on primary dysmenorrhea: a clinical controlled trial. Journal of midwifery \& women's health. 2009 Sep 10; 54(5): 401-4 p.

[22] Borrelli F, Ernst E. Alternative and complementary therapies for the menopause. Maturitas. 2010 Aug 1; 66(4): 333-43 p.

[23] Mirabi P, Alamolhoda SH, Esmaeilzadeh S, Mojab F. Effect of medicinal herbs on primary dysmenorrhoea-a systematic review. Iranian journal of pharmaceutical research: IJPR. 2014; 13(3): 757-767 p.

[24] Muley B, Khadabadi S, Banarase N. Phytochemical Constituents and Pharmacological Activities of Calendula officinalis Linn (Asteraceae): A Review. Tropical Journal of Pharmaceutical Research .African Journals Online (AJOL); 2009; 8 (5): 455-465 p.

[25] RaisiDehkordi Z, Hosseini Baharanchi FS, Bekhradi R. Effect of lavender inhalation on the symptoms of primary dysmenorrhea and the amount of menstrual bleeding: A randomized clinical trial. Complementary Therapies in Medicine.2014; 22(2):212-9 p.

[26] Gupta. Chamomile: An herbal medicine of the past with a bright future (Review). Molecular Medicine Reports. 2010; 3(6):895-901 p.

[27] Mahboubi M. Foeniculum vulgare as Valuable Plant in Management of Women's Health. Journal of menopausal medicine. 2019; 25(1):1-4 p.

[28] Bahmani M, Eftekhari Z, Jelodari M, Saki K, Abdollahi R, Majlesi M, Rafieian Kopaei M, Rasouli S. Effect of Iranian herbal medicines in dysmenorrhea phytotherapy. Journal of Chemical and Pharmaceutical Research. 2015(2):519-26 p.

[29] Mirabi P, Dolatian M, Mojab F, Majd HA. Effects of valerian on the severity and systemic manifestations of dysmenorrhea. International Journal of Gynecology\& Obstetrics. 2011; 115(3): 285-8 p.

[30] Saki K, Bahmani M, Rafieian-Kopaei M, Hassanzadazar H, Dehghan K, Bahmani F, Asadzadeh J. The most common native medicinal plants used for psychiatric and neurological disorders in Urmia city, northwest of Iran. Asian Pacific Journal of Tropical Disease. 2014 1; (4): S895-901 p.

[31] Bashir S, Memon R, Gilani AH. Antispasmodic and antidiarrheal activities of Valeriana hardwickii Wall. Rhizomeare putatively mediated through calcium channel blockade. Evidence-Based Complementary and Alternative Medicine. 2011 (2011): 1-6 p.
[32] Bahmani M, Eftekhari Z, Jelodari M, Saki K, Abdollahi R, Majlesi M, Rafieian Kopaei M, Rasouli S. Effect of Iranian herbal medicines in dysmenorrhea phytotherapy. Journal of Chemical and Pharmaceutical Research. 2015(2): 519-26 p.

[33] Jenabi E, Fereidoony B. Effect of achillea millefolium on relief of primary dysmenorrhea: a double-blind randomized clinical trial. Journal of pediatric and adolescent gynecology. 2015; 28(5):402-4 p.

[34] Jahangirifar M, Taebi M, Dolatian M. The effect of Cinnamon on primary dysmenorrhea: a randomized, double-blind clinical trial. Complementary therapies in clinical practice. 2018; 33: 56-60 p.

[35] Gruenwald J, Freder J, Armbruester N. Cinnamon and health. Critical reviews in food science and nutrition. 2010; 50(9): 822-34 p.

[36] Pellow J, Nienhuis C. Medicinal plants for primary dysmenorrhoea: A systematic review. Complementary therapies in medicine. 2018;(37): 13-26 p.

[37] Uritu CM, Mihai CT, Stanciu G-D, Dodi G, Alexa-Stratulat T, Luca A, et al. Medicinal Plants of the Family Lamiaceae in Pain Therapy: A Review. Pain Research and Management .2018 8; (2018): 1-44 p.

[38] Monji F, Hashemian F, Salehi Surmaghi M-H, Mohammadyari F, Ghiyaei S, Soltanmohammadi A. Therapeutic Effects of Standardized Formulation of Stachys lavandulifolia Vahl on Primary Dysmenorrhea: A Randomized, Double-Blind, Crossover, Placebo-Controlled Pilot Study. The Journal of Alternative and Complementary Medicine [Internet]. Mary Ann Liebert Inc; 2018 Nov; 24(11): 1092-8 p.

[39] Boskabady MH, Alitaneh S, Alavinezhad A Carumcopticum L.: a herbal medicine with various pharmacological effects. BioMed research international. (2014): 1-11p.

[40] Dehghan M, Asgharian S, Khalesi E, Ahmadi A, Lorigooini Z. Comparative study of the effect of Thymus daenensis gel $5 \%$ and diclofenac in patients with knee osteoarthritis. BioMedicine .2019 May 24; 9(2):9p.

[41] Tiwari P, Pratap Kumar Sahu PK. Plants altering hormonal milieu: A review. Asian Pacific Journal of Reproduction .Asian Pacific Journal of Tropical Medicine Press; 2017 Mar 1; 6(2): 49-53 p.

[42] Hosseini Z, Lorigooini Z, Rafieian-Kopaei M, Shirmardi HA, Solati K. A review of botany and pharmacological effect and chemical composition of Echinophora species growing in Iran. Pharmacognosy research. 2017; 9(4): 305 p.

[43] Delaram M, Kheiri S, Hodjati MR. Comparing the effects of echinophora-platyloba, fennel and placebo on pre-menstrual syndrome. Journal of reproduction \& infertility. 2011; 12(3): 221 p .

[44] Bahmani M, Rafieian Kopaei M, Saki K, Majlesi M, Bahmani F, Sharifi A, Rasouli S, Sepahvand R, Abdollahi R, Moghimi Monfared $\mathrm{O}$, Baharvand S. Identification of medical plants acting on reproductive system disorders: An ethnobotanical study in Urmia, Northwest of Iran. Journal of Chemical and Pharmaceutical Research. 2015(2): 493-502 p.

[45] Canning S, Waterman M, Orsi N, Ayres J, Simpson N, Dye 
L. The Efficacy of Hypericum perforatum (St John'sWort) for the Treatment of Premenstrual Syndrome. 2010; 24(3): 207-25 p.

[46] Stevinson C, Ernst E. A pilot study of Hypericum perforatum for the treatment of premenstrual syndrome. BJOG: An International Journal of Obstetrics and Gynaecology. 2000; 107(7): 870-6 p.

[47] Ketnawa S, Rawdkuen S. Application of bromelain extract for muscle foods tenderization. Food and Nutrition Sciences. 2011; 2(05): 393 p.

[48] Walker AF, Bundy R, Hicks SM, Middleton RW. Bromelain reduces mild acute knee pain and improves well-being in a dose-dependent fashion in an open study of otherwise healthy adults. Phytomedicine. 2002; 9(8): 681-6 p. 